\title{
ANALISIS PENDAPATAN USAHATANI PADI DI BANTARAN SUNGAI KRUENG ACEH KECAMATAN INGIN JAYA KABUPATEN ACEH BESAR
}

\author{
Analysis Of Rice Farm Income In River Plains Krueng Aceh Kecamatan Ingin Jaya \\ Kabupaten Aceh Besar
}

\author{
Liza Epriana, Irwan A Kadir ${ }^{1}$, Azhar $^{1 *}$ \\ ${ }^{1}$ Program Studi Agribisnis, Fakultas Pertanian, Universitas Syiah Kuala
}

\begin{abstract}
Abstrak. Usahatani padi di Ingin Jaya pada umumnya dilakukan pada lahan sawah, namun dalam hal ini petani memanfaatkan dengan baik lahan tanah di Bantaran Sungai Krueng Aceh di Kecamatan Ingin Jaya Kabupaten Aceh Besar untuk menanam padi, sehingga usahatani padi ini dapat memberikan pendapatan yang baik bagi petani itu sendiri. Penelitian ini bertujuan untuk mengetahui besarnya pendapatan usahatani padi di Bantaran Sungai Krueng Aceh dapat memberikan pendapatan yang layak bagi petani. Metode yang digunakan dalam penelitian ini yaitu Metode Sensus. Analisis pendapatan usahatani tersebut membutuhkan biaya produksi sebesar Rp 10.303.062,-/Ha/MT, total penerimaan (TR) sebesar Rp 21.645.288,-/Ha/MT, pendapatan usahatani diperoleh sebesar $\mathrm{Rp}$ 11.342.226/Ha/MT, R/C didapat sebesar 2,1 (bermakna usahatani padi tersebut menguntungkan atau layak diusahakan).
\end{abstract}

Kata kunci: Usahatani Padi, Pendapatan usahatani

Abstract.Rice farming in Ingin Jaya is generally carried out on paddy fields, but in this case farmers make good use of land on the Krueng Riverbank in Aceh in the District of Want Jaya, Aceh Besar District to grow rice, so that rice farming can provide good income for farmers own. This study aims to determine the amount of rice farming income in the Krueng River Basin in Aceh can provide a decent income for farmers. The method used in this study is the Census Method. Analysis of farm income requires production costs of Rp. 10,303,062, - / Ha / MT, total revenue (TR) of Rp. 21,645,288, - / Ha / MT, farm income is Rp. 11,342,226 / Ha / MT, R / C obtained by 2.1 (meaning that rice farming is profitable or feasible to cultivate).

Keywords: Rice farming, Revenue farming

\section{PENDAHULUAN}

Padi adalah komoditas utama yang berperan sebagai pemenuh kebutuhan pokok sebagai karbohidrat bagi penduduk. Komoditas inimemiliki peranan pokok sebagai pemenuhan kebutuhan pangan utama yang setiap tahunnya meningkat sebagai akibat pertambahan jumlah penduduk yang besar, serta berkembangnya industri pangan dan pakan. Pada dasarnya penanaman padi dilakukan di lahan sawah baik bertadah hujan maupun irigasi. Di Bantaran Sungai Kecamatan Ingin Jaya Kabupaten Aceh Besar tepatnya di Desa Bada memiliki luas lahan untuk penananam padi sebesar $9 \mathrm{Ha}$, yang merupakan lahan milik pemerintah yang dimanfaatkan oleh penduduk sekitar untuk melakukan penanaman padi. Hingga saat ini para pelaku petani berjumlah 12 orang.

Umumnya petani menerapkan pola dan jadwal penanaman padi bedasarkan pengalaman. Namun dengan perubahan cuaca yang terjadi saat ini, pola dan jadwal tanam yang biasanya diterapkan petani sudah tidak dapat diperlakukan seperti biasanya. Seringkali lahan petani mengalami kekeringan akibat salah memprediksi cuaca yang pada akhirnya berdampak pada pendapatan petani. Petani di Bantaran Krueng Aceh di Kecamatan Ingin Jaya mengubah tanah di Bantaran sungai untuk dijadikan areal penanaman padi. Apabila curah hujan kurang terpenuhi petani memanfaatkan air sungai untuk mengairi lahan sistem dengan cara memanfaatkan sungai untuk mendapatkan pendapatan yang lebih baik, sehingga padi dapat ditanam dua kali dalam satu tahun. 
Pada dasarnya penanaman padi dilakukan di lahan sawah baik bertadah hujan maupun irigasi. Namun demikian penanaman padi juga dilakukan di lahan bantaran Krueng Aceh Kecamatan Ingin Jaya. Sampai sejauh ini belum ada informasi di Provinsi Aceh yang mengungkapkan besarnya pendapatan dan produksi padi yang ditanam di Bantaran Sungai Krueng Aceh. Tujuan penelitian untuk mengetahui besarnya pendapatan usahatani padi di Bantaran Sungai Krueng Aceh dapat memberikan pendapatan yang layak bagi petani.

\section{Lokasi dan Waktu Penelitian}

\section{METODE PENELITIAN}

Tempat penelitian ini dilaksanakan di Bantaran Sungai Krueng Aceh Kecamatan Ingin Jaya Kabupaten Aceh Besar. Penentuan lokasi penelitian ini ditentukan secara sengaja (Purposive) dengan pertimbangan daerah tersebut merupakan salah satu daerah penanaman usahatani padi di Bantaran yang terindikasi adanya pemanfaatan tanah bantaran sungai sebagai lahan penanaman usahatani padi. Adapun waktu penelitian berlangsung dari bulan Oktober 2017 hingga selesai.

\section{Objek dan Ruang Lingkup Penelitian}

Objek penelitian ini adalah petani yang berusahatani padi di Bantaran Sungai Krueng Aceh. Ruang lingkup penelitian ini dibatasi pada analisis pendapatan usahatani padi di Bantaran Sungai Krueng Aceh.

\section{Sumber dan Metode Pengumpulan Data}

Metode yang digunakan dalam penelitian ini yaitu Metode Sensus, dimana seluruh populasi akan dijadikan sebagai data penelitian. Hal ini didasarkan pada penggunaan lahan Bantaran Sungai Krueng Aceh di Kecamatan Ingin Jaya Kabupaten Aceh Besar yang dijadikan tempat penanaman padi. Metode Sensus adalah teknik penentuan sampel bila semua anggota populasi digunakan sebagai sampel

\section{Model Analisis}

\section{A. Biaya Produksi}

$$
\mathrm{TC}=\mathrm{TFC}+\mathrm{TVC}
$$

Keterangan:

$\mathrm{TC}=$ Total biaya produksi $(\mathrm{Rp} / \mathrm{MT})$

TFC = Total biaya tetap $(\mathrm{Rp} / \mathrm{MT})$

$\mathrm{TVC}=$ Total biaya variabel $(\mathrm{Rp} / \mathrm{MT})$

\section{B. Penerimaan}

Keterangan:

$$
\mathrm{TR}=\mathrm{Y} . \mathrm{PY}
$$

$\mathrm{TR}=$ Total penerimaan $(\mathrm{Rp} / \mathrm{MT})$

$\mathrm{Y} \quad=$ Produksi $(\mathrm{Kg} / \mathrm{MT})$

$\mathrm{PY} \quad=$ Harga produk $(\mathrm{Rp} / \mathrm{Kg})$

\section{Pendapatan}

Keterangan:

$\mathrm{I} \quad=$ Pendapatan $(\mathrm{Rp} / \mathrm{MT})$

$\mathrm{TR}=$ Total penerimaan $(\mathrm{Rp} / \mathrm{MT})$ 
$\mathrm{TC}=$ Total biaya $(\mathrm{Rp} / \mathrm{MT})$

\section{Revenue Cost Ratio (R/Ratio)}

Revenue Cost Ratio adalah nilai yang didapatkan dari perbandingan antara penerimaan dan biaya produksi. Rumus untuk analisis ini adalah sebagai berikut:

$$
\mathrm{R} / \mathrm{C}=\frac{\text { Total penerimaan }}{\text { Total biaya produksi }} \ldots . . . .(\text { Tim Penulis Penebar Swadaya, 2008) }
$$

Dengan kriteria keputusan sebagai berikut:

1. Bila $\mathrm{R} / \mathrm{C}>1$, maka usahatani padi layak diusahakan.

2. Bila $\mathrm{R} / \mathrm{C}<1$, maka usahatani padi tidak layak dikembangkan (mengalami kerugian).

3. Bila $\mathrm{R} / \mathrm{C}=1$, maka usahatani padi tersebut berada pada titik impas.

\section{HASIL PENELITIAN DAN PEMBAHASAN}

Adapun hasil penelitian ini adalah sebagai berikut :

Tabel 1. Rata-rata Penggunaan Peralatan Produksi Usahatani Padi di Bantaran Sungai Krueng Aceh Kecamatan Ingin Jaya, Tahun 2017

\begin{tabular}{cccccc}
\hline No & Jenis Alat & $\begin{array}{c}\text { Jumlah } \\
\text { (Unit/Ha) }\end{array}$ & $\begin{array}{c}\text { Harga } \\
(\mathbf{R p / U n i t )}\end{array}$ & $\begin{array}{c}\text { Umur } \\
\text { Ekonomis } \\
\text { (Bulan) }\end{array}$ & $\begin{array}{c}\text { Biaya Penyusutan } \\
\text { (Rp/Ha/MT) }\end{array}$ \\
\hline 1 & Garu & 1 & 40.000 & 24 & 1.667 \\
2 & Cangkul & 1 & 70.000 & 24 & 3.646 \\
3 & Sprayer & 1 & 125.000 & 60 & 2.083 \\
4 & Pompa Air & 1 & 225.000 & 48 & 4.688 \\
\hline Jumlah Biaya (Rp/MT) & & & & 12.084 \\
Sumber: Data Primer (Diolah), 2017 & & &
\end{tabular}

Tabel 1 menunjukan bahwa rata-rata biaya penyusutan untuk alat pompa air per satuan luas Hektar merupakan biaya penyusutan alat terbesar dibandingkan dengan rata-rata biaya penyusutan alat lainnya yaitu $\mathrm{Rp}$ 4.688. Sedangkan biaya penyusutan garu merupakan biaya penyusutan terendah yaitu $\mathrm{Rp} 1.667$. Hal ini dikarenakan harga rata-rata pompa air paling tinggi dibandingkan alat lainnya. Sedangkan harga rata-rata alat lainnya lebih rendah.

Tabel 2. Rata-rata Biaya Variabel pada Usahatani Padi di Bantaran Sungai Krueng Aceh Kecamatan Ingin Jaya, Tahun 2017

\begin{tabular}{clccc}
\hline No. & Sarana Produksi & Satuan & $\begin{array}{c}\text { Jumlah } \\
\text { Satuan }\end{array}$ & Biaya (Rp/Ha/MT) \\
\hline 1. & Benih & Kilogran $(\mathrm{Kg} / \mathrm{Ha} / \mathrm{MT})$ & 19 & 65.625 \\
2. & Pupuk: & Kilogram $(\mathrm{Kg} / \mathrm{Ha} / \mathrm{MT})$ & 113 & 202.500 \\
& UUrea & Kilogram $(\mathrm{Kg} / \mathrm{Ha} / \mathrm{MT})$ & 50 & 350.000 \\
& KKCL & Kilogram $(\mathrm{Kg} / \mathrm{Ha} / \mathrm{MT})$ & 200 & 600.000 \\
& SSP 36 & Liter $(\mathrm{L} / \mathrm{Ha} / \mathrm{MT})$ & 2 & 187.500 \\
3. & Hama & Liter $(\mathrm{L} / \mathrm{Ha} / \mathrm{MT})$ & 2 & 127.292 \\
4. & Gulma & Total biaya $(\mathrm{Rp})$ & 1.532 .917 \\
\hline
\end{tabular}

Sumber: Data Primer (Diolah), 2017

Tabel 2 menunjukkan bahwa rata-rata pengeluaran terbesar untuk sarana produksi terdapat pada penggunaan pupuk SP 36 yaitu Rp $600.000 \mathrm{Kg} / \mathrm{Ha} / \mathrm{MT}$ dengan jumlah 200 $\mathrm{Kg} / \mathrm{Ha} / \mathrm{MT}$. Sedangkan untuk penggunaan sarana produksi dengan biaya terendah yang dikeluarkan oleh petani adalah untuk pupuk urea yaitu Rp $65.625 \mathrm{Kg} / \mathrm{Ha} / \mathrm{MT}$ dengan jumlah penggunaan $113 \mathrm{Kg} / \mathrm{Ha} / \mathrm{MT}$. Sarana produksi khususnya benih dan pupuk pada usahatani 
padi di Bantaran Sungai Krueng Aceh Kecamtan Ingin Jaya ini, masih didapatkan petani dengan harga subsidi yang berasal dari Anggaran Pendapatan dan Belanja Negara (APBN).

Tabel 3. Rata-rata Penggunaan Tenaga Kerja pada Kegiatan Usahatani Padi di Bantaran Sungai Krueng Aceh Kecamatan Ingin Jaya, Tahun 2017

\begin{tabular}{|c|c|c|c|c|c|}
\hline \multirow[t]{2}{*}{ No } & \multirow[t]{2}{*}{ Jenis Kegiatan } & \multicolumn{2}{|c|}{$\begin{array}{c}\text { Sumber Tenaga } \\
\text { Kerja (HKP) }\end{array}$} & \multirow{2}{*}{$\begin{array}{c}\text { Jumlah } \\
\text { (HKP) }\end{array}$} & \multirow[t]{2}{*}{ Persentase $(\%)$} \\
\hline & & LK & DK & & \\
\hline 1. & Pengolahan Tanah & 37,5 & 0 & 37,5 & 39 \\
\hline 2. & Penyemaian Benih & 0 & 1,31 & 1,31 & 1 \\
\hline 3. & Penanaman & 0 & 22,5 & 22,5 & 24 \\
\hline 4. & Pengendalian HPT & 0 & 3,21 & 3,21 & 2 \\
\hline 5. & Pemupukan & 0 & 1,6 & 1,6 & 3 \\
\hline 6 & Pencabutan rumput & 0 & 3,27 & 3,27 & 3 \\
\hline 7. & Pemanenan & 0,3 & 25,5 & 25,8 & 28 \\
\hline Jumlah & & & & 95,19 & 100 \\
\hline
\end{tabular}

Sumber: Data Primer (Diolah), 2017

Berdasarkan Tabel 3 dapat dilihat bahwa rata-rata penggunaan tenaga kerja pada usahatani padi di Bantaran Sungai Krueng Aceh Kecamatan Ingin Jaya adalah sebesar 95,19 HKP dengan total biaya sebesar Rp 5.221.886 untuk satu kali masa tanam. Persentase penggunaan tenaga kerja paling besar terdapat pada kegiatan pengolahan tanah yaitu $39 \%$. Hal ini dikarenakan untuk kegiatan pengolahan tanah dilakukan sebanyak dua kali, sehingga nilai HKP untuk kegiatan pengolahan tanam lebih besar dari kegiatan lainnya.

Tabel 4. Rata-rata Penggunaan Biaya-Biaya Lain Usahatani Padi di Bantaran Sungai Krueng Aceh Kecamatan Ingin Jaya, Tahun 2017

\begin{tabular}{llc}
\hline No. & Jenis Biaya & Jumlah $(\mathbf{R p} / \mathbf{H a} / \mathbf{M T})$ \\
\hline 1. & Biaya Pengairan & 856.667 \\
2. & Biaya perontokan padi & 2.164 .529 \\
\hline & Total Biaya $(\mathbf{R p})$ & $\mathbf{3 . 0 2 1 . 1 9 6}$ \\
\hline
\end{tabular}

Sumber: Data Primer(Diolah), 2017

Dari tabel 4 dapat dilihat bahwa jenis biaya untuk perontokkan padi merupakan biaya yang dikeluarkan paling besar dibandingkan dengan biaya untuk pengairan, yaitu Rp2.164.529/Ha/MT. untuk perontokkan padi, petani didaerah penelitian pada umumnya membayar sebesar Rp 520/Kg. sistem pembayaran dari perontokkan padi ini adalah pemberian hasil gabah itu sendiri, dengan rata-rata hasil produksi per masa tanam adalah 4.162, $\mathrm{Kg} / \mathrm{Ha}$.

Tabel 5. Rata-rata Penggunaan Biaya Produksi pada Lain Usahatani Padi di Bantaran Sungai Krueng Aceh Kecamatan Ingin Jaya, Tahun 2017

\begin{tabular}{|c|c|c|c|c|}
\hline \multirow[b]{2}{*}{ No } & \multirow[b]{2}{*}{ Jenis Biaya } & \multicolumn{2}{|c|}{ Biaya Produksi (Rp) } & \multirow[b]{2}{*}{ Nilai Total } \\
\hline & & $\begin{array}{l}\text { Biaya Variable } \\
\text { (Variable Cost) }\end{array}$ & $\begin{array}{c}\begin{array}{c}\text { Biaya Tetap } \\
\text { (Fixed Cost) }\end{array} \\
\end{array}$ & \\
\hline 1. & Sarana Produksi & 2.043 .889 & 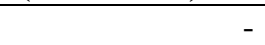 & \\
\hline 2. & Tenaga Kerja & 5.218 .444 & - & \\
\hline 3. & Penyusutan Alat & & 16.111 & \\
\hline \multirow[t]{2}{*}{4.} & Biaya-biaya Lain & 3.021 .195 & - & \\
\hline & Jumlah (Rp) & 10.283 .528 & 16.111 & 10.299 .639 \\
\hline
\end{tabular}

Sumber: Data Primer (Diolah), 2017 
Berdasarkan Tabel 5 dapat diketahui bahwa besar biaya produksi rata-rata yang dikeluarkan oleh petani adalah sebesar Rp 10.286.951/Ha/MT. Biaya produksi paling besar yang dikeluarkan oleh petani terdapat pada biaya penggunaan tenaga kerja yaitu sebesar Rp 5.218.444/Ha/MT dan biaya terendah yang dikeluarkan adalah biaya penyusutan alat pertanian yaitu sebesar Rp 16.111/Ha/MT.

Tabel 6. Rata-rata Produksi dan Total Penerimaan Usahatani Padi di Bantaran Sungai Krueng Aceh Kecamatan Ingin Jaya.

\begin{tabular}{clcrr}
\hline \multirow{2}{*}{ No. } & \multicolumn{2}{c}{ Keterangan } & Satuan & \multicolumn{2}{c}{ Jumlah Rata-Rata } \\
\multicolumn{1}{l}{} & Luas Lahan & $\mathrm{Ha}$ & 1 & \multicolumn{1}{c}{ Per 1 Ha } \\
\hline 2. & Produksi & $\mathrm{Kg} / \mathrm{Ha} / \mathrm{MT}$ & 3.122 & 1 \\
3. & Harga Jual & $\mathrm{Rp} / \mathrm{Kg}$ & 5200 & 4.162 \\
4. & Penerimaan & $\mathrm{Rp} / \mathrm{Ha} / \mathrm{MT}$ & 16.233 .967 & 5200 \\
Sumber: & Data Primer (Diolah), 2017 & &
\end{tabular}

Berdasarkan Tabel 6 dapat diketahui bahwa jumlah penerimaan yang diperoleh per petani dari hasil produksi padi sawah yang dilakukan selama satu kali masa tanam adalah sebesar Rp16.233.967/Ha/MT. Sedangkan untuk perhitungan rata-rata per satuan lahan yaitu per 1 ha penerimaan yang diperolah petani adalah sebesar Rp 21.645.288/Ha/MT.

Analisis Pendapatan Usahatani Padi

$$
\begin{aligned}
\mathrm{I} & =\mathrm{TR}-\mathrm{TC} \\
& =\mathrm{Rp} 21.645 .288-\mathrm{Rp} 10.303 .062 \\
& =\operatorname{Rp} 11.343 .266
\end{aligned}
$$

Rata-rata pendapatan usahatani padi sawah di Bantaran sungai Krueng Aceh Kecamatan Ingin Jaya yang diperoleh petani adalah sebesar Rp 11.343.266,-/Ha/MT

Analisis R/C Ratio (Revenue Cost Ratio)

$$
\begin{gathered}
R / C=\frac{\text { Total penerimaan }}{\text { Total biaya produksi }} \\
=\frac{21.645 .288}{10.303 .062} \\
=2,1 \quad
\end{gathered}
$$

Hasil perhitungan menunjukkan nilai R/C Ratio adalah sebesar 2,1 yang berarti bahwa nilai R/C Ratio hitung lebih besar dari $1(\mathrm{R} / \mathrm{C}>1)$. Sehingga dapat disimpulkan bahwa usahatani padi sawah di Bantaran Sungai Krueng Aceh Kecamatan Ingin Jaya adalah menguntungkan atau layak untuk diusahakan oleh petani. Nilai R/C Ratio sebesar 2,1 juga menunjukkan bahwa setiap pengeluaran dari petani sebesar Rp. 1/Ha/MT yang digunakan untuk biaya produksi usahatani padi maka akan menambah penerimaan bagi petani sebesar Rp. 2,1/Ha/MT.

\section{Simpulan}

\section{SIMPULAN DAN SARAN}

Berdasarkan hasil analisis yang telah dilakukan, kesimpulan yang diperoleh usahatani padi di Bantaran Sungai Krueng Aceh Kecamatan Ingin Jaya dapat memberikan pendapatan yang layak bagi petani. Hal ini bedasarkan hasil perhitungan pendapatan yang menunjukan 
bahwa pendapatan bersih diperoleh sebesar Rp 11.342.226/Ha/MT, dengan nilai R/C = 2,1 artinya usahatani padi di Bantaran Sungai Krueng Aceh Kecamatan Ingin Jaya layak diusahakan dan memberi keuntungan bagi petani.

\section{Saran}

Berikut beberapa masukan yang dapat mejadi pertimbangan guna perbaikan dimasa mendatang Usahatani padi di Bantaran Sungai Krueng Aceh perlu dikembangkan karena dapat meningkatkan pendapatan petani dan lapangan kerja di daerah tersebut.

\section{DAFTAR PUSTAKA}

Abdul, R. 2010. Fiqh Muamalah, Kencana.Jakarta

Ambo Tuwo, 2011, Pengelolaan Ekowisata Pesisir dan Laut Brillian Internasional. Makassar.

Barokah, Umi. 2014. Analisis Biaya dan Pendapatan Usahatani Padi di Kabupaten Karanganyar. Program Studi Agribisnis Vol. 26 No. 1 \& No. 2. Fakultas Pertanian Universitas Sebelas Maret. Surakarta. hi Petani untuk Menanam Padi Hibrida (Studi Kasus Kecamatan Cibuaya, Kabupaten Kerawang Jawa Barat). Skripsi. Program StudiManajemen Agribisnis. Fakultas Pertanian. IPB. Bogor.

Basuki. 2008. Analisis Pendapatan Usahatani Padi dan Faktor-faktor yang Mempengaruhi Petani untuk Menanam Padi Hibrida (Studi Kasus Kecamatan Cibuaya, Kabupaten Kerawang Jawa Barat). Skripsi. Program Studi Manajemen Agribisnis. Fakultas Pertanian. IPB. Bogor.

BPS. 2016. Aceh Besar Dalam Angka 2016. Badan Pusat Statistik Provinsi Aceh.

Darius, Saipul Bahri dan Ujang Paman. 2015. Analisis Ekonomi Usahatani Padi Sawah di Kecamatan Rambah Samo Kabupaten Rokan Hulu. Jurnal Dinamika Pertanian 161 XXX Kecamatan Rambah Samo Kabupaten Rokan Hulu. Jurnal Dinamika Pertanian $161 \mathrm{XXX}$.

Hasyim, H. 2006. Analisis Hubungan Faktor Sosial, Ekonomi Petani terhadap Program Penyuluhan Pertanian. Laporan Hasil Penelitian. Universitas Sumatera Utara. Medan.

Oktaviani, L. 2016. Analisis Pendapatan dan Faktor-faktor yang Mempengaruhi Minat Petani Terhadap Usahatani Padi Sawah di Kecamatan Meureubo Kabupaten Aceh Barat. Skripsi. Program Studi Agribisnis. Fakultas Pertanian. Universitas Syiah Kuala.

Rahim. Abd. dan. Hastuti. DRW. 2007. Ekonomi Pertanian. Penebar Swadaya. Jakarta.

Soekartawi. 2002. Analisis Usahatani. Jakarta. Universitas Indonesia.

Sudarsono. 2001. Pokok-pokok Hukum Islam. Rineka Cipta. Jakarta.

Sugiyono, (2008). Metode Penelitian Kunatitatif Kualitatif dan R\&D. Bandung.

Popidylah, Radian, Adi Suyatno. 2015. Analisis Pendapatan Usahatani Padi di Desa SungaiKinjil Kecamatan Benua Kayung Kabupaten Ketapang. Jurnal Sosial Ekonomi Pertanian. Vol.4 Nomor 2. Fakultas Pertanian Universitas Tanjungpura. Pontianak.

Tim Penulis Penebar Swadaya. 2008. Agribisnis Perikanan: Penebar Swadaya. Jakarta. 
Yasa, Nyoman Artika, Hadayani. 2017. Analisis Produksi dan Pendapatan Usahatani Padi Sawah di Desa Bonemarawa Kecamatan Riopakava Kabupaten Donggala. Program Studi Agribisnis. Vol.1 No. 111-118. Fakultas Pertanian Universitas Tadulako. Palu.

Yusuf, A dan Harnowo, D. 2010. Teknologi Budidaya Padi sawah Mendukung Sl-PTT. BPTP. Sumatera Utara.

Zulmi, R. 2011. Pengaruh Luas Lahan, Tenaga Kerja, Penggunaan Benih dan Pupuk Terhadap Produksi Padi di Jawa Tengah Tahun 1994-2008. Skripsi. Fakultas Ekonomi Universitas Diponegoro, Semarang. 